Kabul: 13 Mayıs 2012

Alındı: 12 Ocak 2012

Web Yayın: 10 Temmuz 2012

Cilt: 1

Sayı: 1

Sayfa: 45 - 52

Mayıs 2012

\title{
Ortalama gravite anomalilerinin enterpolasyonunda basit ve tamamlanmış Bouguer yaklaşımının karşılaştırılması
}

\author{
Ramazan Alpay Abbak ${ }^{1}$, Aydın Üstün ${ }^{1, *}$, Artu Ellmann ${ }^{2}$ \\ 1 Selçuk Üniversitesi, Mühendislik Mimarlık Fakültesi, Harita Mühendisliği Bölümü, Konya. \\ 2 Talin Teknoloji Üniversitesi, Inşaat Fakültesi, Ulaşım Mühendisliği Bölümü, Talin, Estonya. \\ Özet
}

Yeryuvarının gerçek şekli olan jeoidin $1 \mathrm{~cm}$ doğrulukla belirlenmesi, günümüz jeodezi topluluğunun en önemli hedeflerinden biridir. Gravimetrik jeoit belirleme belirtilen hedefe ulaşmak için tercih edilen yöntemlerin başında gelir. Ne var ki; fiziksel yeryüzünde ölçülen gravite değerleri jeoit belirleme sürecine doğrudan dahil edil(e) mez. Yüzey gravite değerlerinin öncelikle gravite anomalilerine indirgenmesi, bu işlem sırasında verilerin toplandiğ yeryüzü parçasının topoğrafik niteliklerini yitirmemesi istenir. Öte yandan, düzenli bir grid verisi oluşturmak için enterpolasyonda dayanak verisi olarak kullanılacak gravite anomalilerinin topoğrafyaya bağımlılığı en alt düzeyde olmalıdır. Boşlukta gravite anomalileri jeoit modellemenin temel veri grubunu oluştururken, daha yumuşak bir yeryuvarl şeklini betimleyen Bouguer anomalileri ise gravite verilerinin enterpolasyonuna elverişlidir. Uygulamada basit Bouguer anomalileri yaygın kullanıma sahip olsa da, düzensiz topoğrafik alanların bozucu etkilerini az ya da çok içerdikleri bilinmektedir. Bu çalışmada basit ve tamamlanmıs Bouguer anomalileri arasındaki farklllıklar, bir test alanindaki gravite verileri yardımıyla ortaya konulmuştur. Boşlukta gravite anomalileri üzerinden her iki yaklaşım için elde edilen farklar, topoğrafya ile korelasyonlu olarak 16 mGal'e kadar çıkmaktadır. Bu sonuç, Türkiye gibi düzensiz topoğrafyaya sahip bölgelerde, enterpolasyon işlemlerinde tamamlanmış Bouguer anomalilerinin kullanılması gerektiğini işaret etmektedir.

Anahtar Sözcükler

Jeoit, gravite anomalisi, Bouguer indirgemesi, arazi düzeltmesi, enterpolasyon

\section{Abstract \\ Comparison between simple and complete Bouguer approaches in interpolation of Mean Gravity Anomalies}

Accepted: 13 May 2012

Received: 12 January 2012 Pub.Online: 10 July 2012

Volume: 1

Number: 1

Page: 45 - 52

May 2012
The determination of the geoid, which is a real shape of the Earth, with an accuracy of $1 \mathrm{~cm}$ is one of the most important aim of the today's geodetic community. The gravimetric geoid modeling is the most preferred technique in order to reach to this target. Nevertheless, the gravity values measured on the physical surface of the Earth can not be directly included to this process. First of all, surface gravity values should be reduced to gravity anomalies and, during this step they should not lose their topographic features of the Earth's surface where the data is collected. On the other hand, in order to generate gravity anomalies on a regular grid, it is expected that dependency of gravity anomalies (to be used as reference data in interpolation) to local topography should be minimum. While free-air anomalies are the basic data source for determining the geoid, Bouguer anomalies describing the smoother Earth's shape, are convenient to the interpolation of gravity anomalies. Therefore, the dependence of Bouguer gravity anomalies, which is a main data in the interpolation procedure, should be reduced to minimum. Although the simple Bouguer anomalies are preferred in practice, it is known that they contain more or less the negative effects of irregular topography. In this study, the differences between simple and complete Bouguer anomalies are presented in a test area. It is seen that the differences between free-air anomalies derived from both approximations are numerically increased up to $16 \mathrm{mGal}$, correlated with the topography. This result indicates that complete Bouguer anomalies should be used in interpolation process in regions posing irregular topography, such as Turkey.

Keywords

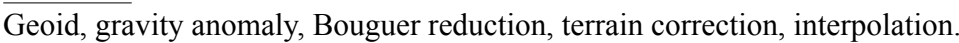




\section{Giriş}

Yerin gravite alanı ve bu alanın eșpotansiyel yüzeylerinden biri olan jeoidin belirlenmesi, fiziksel jeodezinin en bașta gelen ödevleri arasındadır. Yüksek çözünürlüklü ve doğruluklu bir jeoit modelinin, sadece jeodezi değil yer bilimlerinin diğer branşları için de pratik önemi vardır. Fiziksel yeryüzünde meydana gelen kitlesel yer değiştirmelerin (örneğin suyun hareketinin) izlenebilmesi, ancak ideal bir referans yüzeyin tanımlanması ile olanaklıdır.

Belirli bir bölge için jeoit modelleme işlemi üç farklı yöntemle ele alınır. Bunlar; fiziksel yeryüzünde veya kitlelerin dişında (uçaktan) ölçülen gravite verilerine dayanan gravimetrik yöntem, çekül sapmalarını kullanan astro-jeodezik yöntem ve elipsoidal-ortometrik yükseklik farklarını esas alan GNSS/nivelman yöntemleridir (örneğin bkz. Üstün 2001).

Gravimetrik yöntem, bir noktadaki jeoit yüksekliği değerinin Stokes fonksiyonu yardımıyla ağırlıklandırılmış yüzey gravite verilerinin integrasyonu olarak elde edilmesini sağlar (Stokes 1949). Çözüme katılan verilerin teorik olarak tüm yeryuvarına dağılmasının yanı sıra, yeterli sıklıkta ve yüksek doğruluklu olması sonucun doğruluğunu belirleyen unsurlardır.

Fiziksel yeryüzünde ölçülen gravite değerleri $(g)$ yukarıda açıklanan işleme doğrudan dahil edilmez; öncelikle gravite anomalilerine dönüştürülmeleri gerekir. Gerçekte dönüşüm işlemiyle yapılan, gravite verilerindeki bazı bileşenlerin matematiksel olarak ortadan kaldırılmasıdır. $\mathrm{Bu}$ süreç literatürde gravite indirgemesi olarak bilinir. İşin amacına ve uygulanan yaklaşıma göre değişik adlarla anılan çok sayıda indirgeme türünden söz edilebilir. Boşlukta gravite, Bouguer, topoğrafik/isostatik, Rudzki bilinen indirgeme türleridir. Daha fazla bilgi Heiskanen ve Moritz (1984), Torge (1989)'de bulunabilir. Kaldırılan bileşenlerin gerektiğinde yeniden yerine konulması uygulamada sıklıkla karşılaşılan bir durum olduğundan, indirgemeye ilişkin matematiksel esaslar doğru ve gerçeğe uygun bir şekilde tanımlanmalıdır.

Janak ve Vanicek (2005) gravite anomalilerinin enterpolasyonu sırasında tamamlanmış Bouguer anomalilerinin kullanılmasının önemini vurgulamaktadır. Diğer yandan Vanicek vd. $(2001,2004)$ indirgeme eșitliklerinde topoğrafik kitleler için düzlem değil, küresel yeryuvarı modelinin referans alınmasını önermektedir.

$\mathrm{Bu}$ çalışma ile jeoit belirleme amacı doğrultusunda, yersel gravite verilerinin boșlukta gravite anomalilerine dönüştürülmesinde uygulanan işlem adımları sunulmakta; basit ve tamamlanmış Bouguer anomalilerinin indirgeme sonuçları üzerindeki etkileri incelenmektedir. Konya Kapalı Havzasında gerçekleştirilen sayısal uygulama, topoğrafyanın düzenli ve düzensiz olduğu kesimler arasındaki farklılıkları görmek açısından yararlı olacaktır.

\section{Gravite Anomalisi ve Topoğrafya Etkisi}

Jeodezide gravite ölçmeleri yeryuvarının şeklini ve gravite alanını belirlemek için yapılır. Ancak, fiziksel yeryüzünde ölçülen gravite değeri tüm yeryuvarının çekim etkisini içermekle birlikte, ölçülerin yapıldığı yerel topoğrafik yapının kısaca yerel kitlelerin etkisini de gösterir. Yerel etkide kuşkusuz en önemli pay en büyük değişimin gözlendiği düşey doğrultu boyuncadır. Bu anlamda gravite ölçüsünün yapıldı$\breve{g} ı$ noktanın yüksekliği yerin gravite alanı ile ilişkili hesaplamalarda mutlaka göz önüne alınmalıdır.

Belirli bir bölgede gravite verilerinin birlikte değerlendirilebilmesi, onların aynı hesap yüzeyine örneğin deniz düzeyine indirgenmesini veya topoğrafyadan bağımsız duruma getirilmesini gerektirir. Ancak indirgeme işlemi sırasında sayısal olarak ortadan kaldırılan veya değiştirilen topoğrafik kitlelerin graviteye etkisi dikkatle ele alınmalı, uygulama sonuçları fiziksel ve matematiksel gerçeklerle çelişmemelidir. İndirgeme yöntemleri ve Türkiye genelinde gerçekleştirilen uygulamalar için Kılıı̧oğlu vd. (2010)'nin çalışmasına bakılabilir.

Jeodezik uygulamalar açısından iki tür gravite indirgemesinin (veya anomali türünün) öne çıktı̆̆ görülmektedir: boşlukta gravite ve Bouguer indirgemesi. Jeodezide, boşlukta gravite indirgemesi daha çok jeoit modellemeye girdi verisi hazırlamak amacıyla kullanılırken, Bouguer indirgemesi gravite anomalilerinin enterpolasyonu için gereklidir. Jeoit modelleme için boşlukta gravite anomalisi yeterli olmasına karşın, modelleme işlemi gridlenmiş verilere dayandığı durumlarda, grid enterpolasyonu için Bouguer indirgemesinin kullanılması kaçınılmazdır. Enterpolasyonda göz önüne alınması gereken en önemli nokta, gravite verilerinin topoğrafyadan bağımsız hale getirilmesidir.

Gerçek koordinatları belirli fiziksel yeryüzü noktasında ölçülen bir noktanın gerçek gravite $(g)$ değerinin, yaklaşık koordinatlar için hesaplanan normal gravite alanındaki karşıllğı olan normal gravite $(\gamma)$ değerinden farkına gravite anomalisi denir. CGS birim sisteminde $\mathrm{mGal}$ cinsinden ifade edilen anomali, ivmenin fiziksel boyutudur $\left(1 \mathrm{mGal}=10^{-5}\right.$ $\mathrm{m} / \mathrm{s}^{2}$.

\subsection{Boşlukta gravite anomalisi}

Fiziksel jeodezide boşlukta gravite anomalilerine iki farklı yüzey seviyesinden bakııı. Bakış açısı, jeodezik sınır değer probleminin hangi yüzey için tanımlanacağına göre değişir. Problem tellüroit yüzeyinde yükseklik anomalisinin belirlenmesi ise yüzey gravite anomalilerinden (Molodensky yaklaşımı), jeoit yüksekliğinin belirlenmesi ise jeoit seviyesine indirgenmiş anomalilerden (Stokes yaklaşımı) söz edilir. Sonuç olarak her iki yaklaşım da ilgili yüzey üzerindeki gravite değerlerinin bilinmesini gerektirir. İster fiziksel yeryüzü olsun ister jeoit, en kolay biçimde bir nivo elipsoidi ve onun (normal) gravite alanı yardımıyla belirlenebilir. $P$ noktasındaki gerçek gravite ve $Q$ noktasındaki normal gravite alanındaki farklılık (sapma) gradyent vektörler cinsinden,

$$
\Delta \boldsymbol{g}=\operatorname{grad} W-\operatorname{grad} U=\boldsymbol{g}-\boldsymbol{\gamma}
$$

eşitliği ile ifade edilir. (1) eşitliği gerçek ve normal gravite uzayında aynı potansiyel değere sahip iki nokta için gravite vektörlerinin doğrultu ve skaler büyüklük farkını gösterir (Şekil 1). Burada sadece skaler büyüklüklerden söz edilecek olursa, iki farklı seviyedeki gravite anomalisi, 


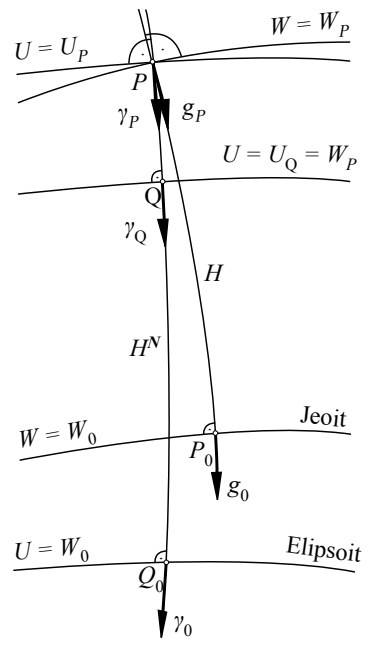

Şekil 1: Yeryüzünde ve jeoit seviyesinde gerçek ve normal gravite vektörleri (Üstün 2008)

$$
\begin{aligned}
& \Delta g=g_{P}-\gamma_{Q}(\text { yeryüzü seviyesinde }) \\
& \Delta g_{0}=g_{0}-\gamma_{0} \text { (jeoit seviyesinde) }
\end{aligned}
$$

eşitlikleri ile gösterilir. Her iki eşitlikten bulunacak sayısal sonuç, uygulamada aynı büyüklüğü işaret eder. Bunun nedeni, fiziksel yeryüzünde ölçülen gravite değerini $\left(g_{p}\right)$ jeoide indirgemek $\left(g_{0}\right)$ ve elipsoit yüzeyindeki normal gravite değerinden $\left(\gamma_{0}\right)$ tellüroit seviyesindeki değerini $\left(\gamma_{Q}\right)$ bulmak için aynı yaklaşımın kullanılmasıdır. Elipsoitten $h$ yükseklikteki bir noktanın normal gravite değeri,

$$
\gamma_{h}=\gamma_{0}+\frac{\partial \gamma}{\partial h} h+\frac{1}{2} \frac{\partial^{2} \gamma}{\partial h^{2}} h^{2}+\ldots
$$

biçiminde Taylor serisine açılabilir. Dizinin terimleri normal gravite alanı parametrelerine göre oluşturulur; doğrusal ve doğrusal olmayan terimler için $\delta g_{F A}$ kısaltması kullanılırsa, (2) ve (3) eşitlikleri tek eşitliğe,

$$
\Delta g_{F A}=g_{P}+\delta g_{F A}-\gamma_{0}
$$

indirgenebilir. $\delta g_{F A}$ boşlukta gravite anomalisi indirgeme büyüklüğünü temsil ettiğinden, $\Delta g_{F A}$ 'ya boşlukta gravite anomalisi adı verilir.

Elipsoit yüzeyinde konumu $\varphi$ elipsoidal enlemi ile gösterilen bir nokta için normal gravite değeri Somigliana (1929)'nın kapalı eşitliği,

$$
\gamma_{0}=\gamma_{e} \frac{1+k \sin ^{2} \varphi}{\sqrt{1-e^{2} \sin ^{2} \varphi}}
$$

ya da bunun seriye açılmış biçimi,

$$
\gamma_{0}=\gamma_{e}\left(1+\alpha_{2} \sin ^{2} \varphi+\alpha_{4} \sin ^{4} \varphi+\alpha_{6} \sin ^{6} \varphi+\alpha_{8} \sin ^{8} \varphi\right)
$$

ile verilir. Burada $\left(\gamma_{e}\right)$ ekvator enlemindeki normal gravite, $\varphi$ noktanın jeodezik enlemi, $\alpha$ değerleri referans elipsoidine ilişkin fiziksel parametrelerdir. Boşlukta indirgeme büyüklüğünün hesaplanmasında, Taylor dizisinin 2. dereceye kadar olan terimleri yeterli görülür. Buna göre 2. dereceden (boşlukta) indirgeme miktarı,

$$
\delta g_{F A}=\frac{2 \gamma_{0}}{a}\left(1+f+m-2 f \sin ^{2} \varphi\right) H-\frac{3 \gamma}{a^{2}} H^{2}
$$

eşitliğinden hesaplanır. Burada $a$ ve $f$ sırasıyla nivo elipsoidinin büyük yarı ekseni ve basıklığını, $m=\omega^{2} a^{2} b / G M$ ile tanımlı jeodezik parametreyi gösterir. Jeodezik uygulamalarda yaygın kullanıma sahip GRS80 ve WGS84 elipsoitleri için (6)-(8) eşitliklerinde geçen jeodezik parametreler Tablo 1'de verilmektedir (Moritz 1992; Anonim 2000).

\subsection{Bouguer anomalisi}

Boşlukta gravite anomalisi, fiziksel yeryüzü ve ortalama deniz yüzeyini temsil eden başlangıç yüzeyi arasında topoğrafik kitlelerin bulunmadığı varsayımına dayanır. Bunun anlamı kitlelerin tamamen yok edilmesi değil, bir şekilde jeoit yüzeyine sıkıştırılması ya da düşünsel olarak bu yüzeyin altına alınmasıdır. Bu yüzden, boşlukta gravite anomalilerinin topoğrafyanın çekim etkisini içermeye devam ettiğinden söz edilebilir. Bağımlılığı ortadan kaldırmanın yolu bu etkinin yeryüzünde ölçülen gravite değerlerinden çıkarılmasıdır. Topoğrafik etki, basit bir yolla sabit yoğunluklu, $H$ yükseklikli ve sonsuza uzanan bir katman yardımıyla göz önüne alınabilir. Bu yaklaşıma basit Bouguer yaklaşımı denir ve boşlukta gravite anomalilerinden çıkarılırsa, basit Bouguer anomalileri,

$$
\begin{aligned}
\Delta g_{S B} & =g_{P}-\delta g_{S B}+\delta g_{F A}-\gamma_{0} \\
& =\Delta g_{F A}-\delta g_{S B} \\
& =\Delta g_{F A}-2 \pi G \rho H
\end{aligned}
$$

elde edilir. Bouguer katmanı için topoğrafik kitlelerin yoğunluk bilgisine gereksinim duyulur ve bunun için çoğu kez ortalama bir değer olarak $2670 \mathrm{~kg} / \mathrm{m}^{3}$ (kaba bir yaklaşım olsa da) kullanılır. (9)'da geçen $G$, Newton'un evrensel çekim sabitidir; $G=6.672585 \times 10^{-11} \mathrm{~kg}^{-1} \mathrm{~m}^{3} \mathrm{~s}^{-2}$ değeri ile bilinir. Sayısal bilgiler eşitlikte yerine konulursa,

$\Delta g_{S B}=\Delta g_{F A}-0.1119 H$

ortaya çıkar. Burada $H^{\prime}$ nin birimi metre olmak üzere sonuç olarak mGal çıkar (Heiskanen ve Moritz 1984).

$\delta g_{S B}$ ile tanımlanan topoğrafyanın çekim etkisi, gerçek durumu yansitmaktan uzaktır. Özellikle dağlık bölgelerde topoğrafik kitlelerin dağılımı, bu plakanın bazen üstünde bazen altındadır; sapma miktarları arazinin yapısına bağlı

Tablo 1: Referans elipsoitlerinin jeodezik parametreleri

\begin{tabular}{|crr|}
\hline \hline Parametre & \multicolumn{1}{c}{ GRS80 } & \multicolumn{1}{c|}{ WGS84 } \\
\hline$a$ & $6378137 \mathrm{~m}$ & $6378137 \mathrm{~m}$ \\
\hline$f$ & 0.0033528106812 & 0.0033528106647 \\
$e^{2}$ & 0.0066943800229 & 0.0066943799901 \\
$K$ & 0.0019318513530 & 0.0019318526524 \\
$M$ & 0.0034497860030 & 0.0034497865068 \\
$\mathrm{~g}_{e}$ & $9.7803267715 \mathrm{~m} / \mathrm{s}^{2}$ & $9.7803253359 \mathrm{~m} / \mathrm{s}^{2}$ \\
$\alpha_{2}$ & 0.0052790414 & 0.0052789940 \\
\hline$\alpha_{4}$ & 0.0000232718 & 0.0000234610 \\
\hline$\alpha_{6}$ & 0.0000001262 & 0.0000001262 \\
\hline$\alpha_{8}$ & 0.0000000007 & 0.0000000007 \\
\hline
\end{tabular}


olarak az ya da çok değişir. Topoğrafyadaki düzensizlikleri kısmen temsil eden ikinci bir düzeltme terimi yardımıyla elde edilmiş anomali değerlerine tamamlanmış ya da rafine edilmiş Bouguer anomalileri,

$$
\Delta g_{C B}=\Delta g_{F A}-\delta g_{S B}+\delta g_{T C}
$$

denir. Eşitlikte geçen $\delta g_{T C}$ arazi düzeltmesi (terrain correction) olarak adlandırılır.

Kolaylık açısından $t=\cos \psi$ ve $d r=r^{\prime} / r$ olmak üzere Martinec (1998)'in önerdiği küresel model için arazi düzeltmesi,

$$
\begin{aligned}
\delta g_{T C} & =r\left(d r^{2} t+3 t+d r-6 t^{2} d r\right)\left(d r^{2}-2 t d r+1\right)^{-1 / 2} \\
& -r\left(-6 t^{2}+4 t+1\right)(2-2 t)^{-1 / 2} \\
& +\left(3 t^{2} r-r\right) \ln \left(\frac{d r-t+\left(d r^{2}-2 t d r+1\right)^{1 / 2}}{1-t+(2-2 t)^{1 / 2}}\right)
\end{aligned}
$$

şeklinde ifade edilebilir. Burada $r=R+H$ ve $r^{\prime}=R+H^{\prime}$ sırasıyla hesap noktası ile integrasyon noktalarının küresel yarıçapını gösterir. Formülün anlamlı sonuçlar verebilmesi için küre üzerinde $3^{\circ}$ yarıçaplı bir alanda topoğrafyanın hesaba katılması yeterli görülür (Martinec 1998 s.49).

\subsection{Boşlukta Gravite Anomalilerin Enterpolasyonu}

Mühendislik uygulamalarında sayısal integrasyon tekniklerine dayalı modelleme işlemlerinde girdi verilerinin eşit aralıklı olması tercih edilir. Benzer durum gravimetrik jeoit belirleme uygulamalarında da geçerlidir. Jeoidin hesaplanacağ1 alandaki gravite anomalilerinin coğrafi grid ağ1 hücrelerinde ortalama değerler biçiminde düzenlenmesi istenir. Literatürde yüksek çözünürlüklü jeoit modeli için çoğunlukla $1^{\prime} \times 1^{\prime}, 2^{\prime} \times 2^{\prime}$ veya $3^{\prime} \times 3^{\prime}$ grid aralığ 1 seçilir. Verilerin yoğunluğuna ve modelin kullanım amacına göre verilen boyutlar değişebilir. Çalışma bölgesinin kutuplara yakın olması durumunda konumsal çözünürlüğün birbirine yaklaşık eşit olması için enlem yönündeki açısal çözünürlük, boylam yönündekinin iki katı olabilir (örneğin $2^{\prime} \times 1^{\prime}$ ). Türkiye gibi orta kuşakta bulunan ülkelerde ise açısal çözünürlük her iki yönde de eşit alınır.

Gravite anomalileri basit ve tamamlanmış Bouguer yardımıyla iki farklı yaklaşımla grid merkezlerine taşınabilir:

- Birinci yaklaşımda, rasgele dağılmış gravite noktalarında (9) eşitliği yardımıyla gravite değerleri basit Bouguer anomalilerine indirgenir. $\mathrm{Bu}$ hesaplama için Bouguer plaka etkisi gravite noktasının topoğrafik yükseklik değeri kullanılır.

- İkinci yaklaşımda, rasgele dağılmış gözlem noktalarındaki anomali değerleri (12) eşitliği yardımıyla Bouguer anomalilerine indirgenir. Yine bu hesaplama için Bouguer plaka etkisi gravite noktasının topoğrafik yükseklik değeri kullanılır. Arazi düzeltmesinin integrasyonu uygun bir yarıçap genişliği seçilerek gerçekleştirilir. Birkaç dereceyi aşmayan integrasyon yarıçapı yeterli doğruluk sağlar.

Yukarıdaki yaklaşımlardan biriyle elde edilen Bouguer anomalileri enterpolasyon işlemine sokularak grid hücrelerindeki değerler türetilir. Gridlenmiş Bouguer anomalilerinden boşluktaki anomali değerlerine geçiş, uygulanan Bouguer indirgemesinin yeniden yerine konulmasıyla sağlanır. Yüksek çözünürlüklü bir sayısal yükseklik modelinden elde edilecek ortalama yükseklik değeri bu amaç için yeterli görülür. Sayısal yükseklik modelinden kaynaklanan hataları en aza indirgemek için arazi düzeltmeleri iki ayrı çözünürlükte ele alınır (Featherstone ve Kirby 2000; Goos vd. 2003). Yukarıda anlatılan indirgeme ve enterpolasyon işlem adımlar1 Şekil 2 ile özetlenmektedir. Şekilde $\Omega$ gravite değerlerinin ölçüldüğü yeryüzünü, $(i, j)$ gravite anomalilerinin gridlenmiş değerlerini temsil etmektedir.

\section{Sayısal Uygulama}

Bu bölümde, yukarıda söz edilen yaklaşımlar sayısal bir uygulama ile irdelenmiştir. Uygulamanın amacı tamamlanmış ve basit Bouguer indirgemesinin boşlukta gravite anomalisi (gridlenmiş) üzerindeki etkilerini ortaya çıkarmak ve topoğrafya göz önüne alınarak farklılığın anlamlılık düzeyini belirlemektir.

\subsection{Uygulama sahası}

Konya, Karaman ve Aksaray illerini içine alan ve Konya Kapalı Havzası olarak adlandırılan bölge, uygulama sahası seçilmiştir. Coğrafi sınırları $37^{\circ} \leq \varphi \leq 39^{\circ}$ kuzey enlemleri, $31.5^{\circ} \leq \lambda \leq 34.5^{\circ}$ doğu boylamları ile belirli çalışma alanı, suyla kaplı alanlar dahil olmak üzere toplam $58.500 \mathrm{~km}^{2}$ 'lik bir yüzölçüme sahiptir. Topoğrafik yapı (Şekil 3) Konya ovası ve Cihanbeyli platosu ile kısmen ovalık, güney ve güneybatıda bu düzlükleri çevreleyen Toros dağları ile dağlık görünümdedir. Ortalama yükseklik 1250 m dolaylarındadır. Havzanın en yüksek noktası $3491 \mathrm{~m}$ ile Toros dağlarının zirvesindedir. En alçak yeri ise $576 \mathrm{~m}$ ile Göksu vadisindedir. Türkiye'nin sayılı büyük göllerinden olan Tuz gölü ve Beyşehir gölü Konya Kapalı Havzası sınırları içerisinde kalmaktadır.

\subsection{Gravite gözlemleri}

Uygulamada kullanılan yüzey gravite değerleri, Türkiye'nin

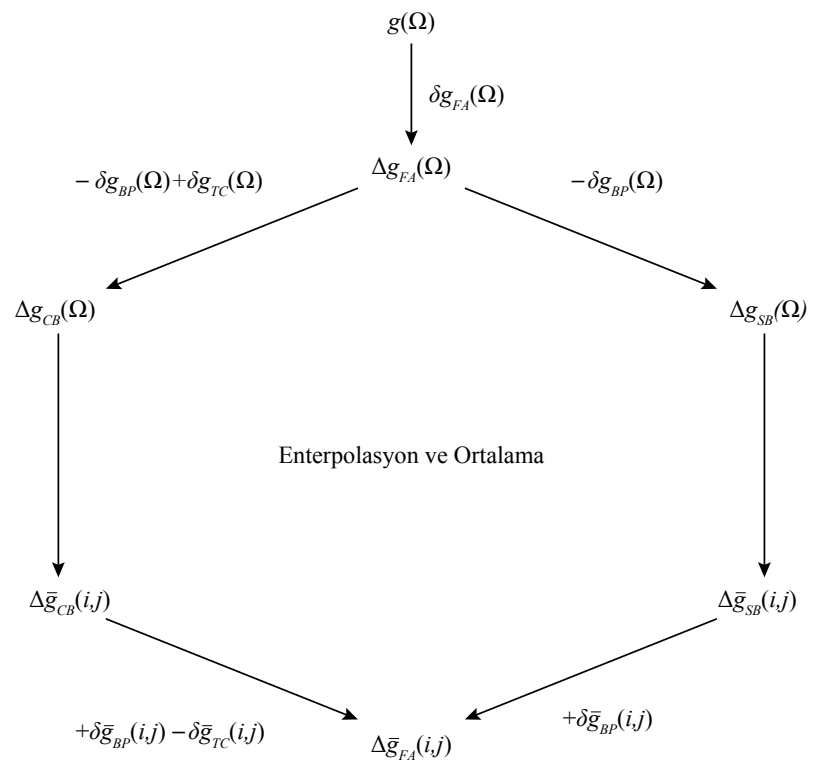

Şekil 2: Jeoit modelleme için (gridlenmiş) boşlukta gravite anomalileri hesaplama adımları (Janak ve Vanicek 2005). 


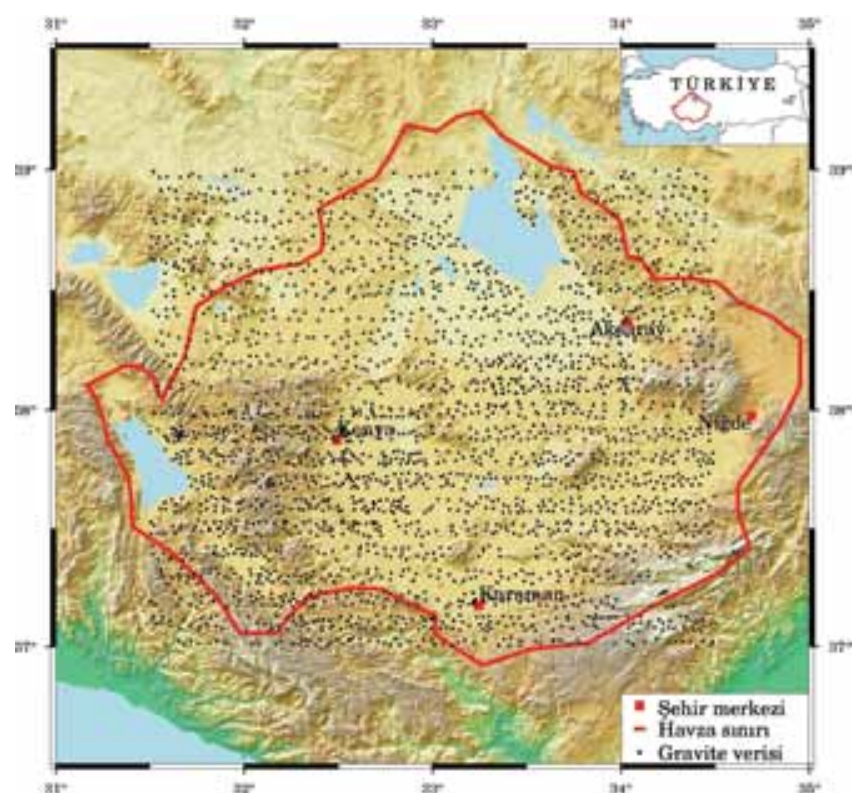

Şekil 3: Uygulama alanının topoğrafik durumu ve gravite verilerinin konumsal dağılımı

gravite veri tabanından sorumlu kuruluş Harita Genel Komutanlığı'ndan satın alınmıştır. Veri dosyasında her satır bir noktaya karşılık gelmekte; bu satırda noktanın coğrafi koordinatları, $\mathrm{mGal}$ cinsinden gravite değeri ve deniz seviyesinden olan yükseklik değeri yer almaktadır. Gravite değerleri International Gravity Standardization Net 1971 (IGSN71), coğrafi koordinatları WGS84, yükseklik bilgisi Türkiye Ulusal Düşey datumundadır. Gravite gözlemlerinin yapıldığı noktaların coğrafi dağılımı Şekil 3'de gösterilmiştir.

Uygulama sahasındaki gravite ölçü sayısı 2681'dir. Veri kümesi, yaklaşı olarak $22 \mathrm{~km}^{2}$ 'lik alana 1 nokta düşecek şekilde bir yoğunluk sunmaktadır. Jeoit belirleme amaçlı benzer çalışmalarla kıyaslandığında veri yoğunluğunun düşük olduğu söylenebilir.

\subsection{Sayısal yükseklik modeli}

2000 yılının Şubat ayında SRTM (Shuttle Radar Topography Mission) projesi kapsamında NASA tarafından yaklaşık $60^{\circ}$ kuzey ve güney enlemleri arasında kalan tüm kara parçalarının yüksek çözünürlüklü sayısal yükseklik modeli üretilmiştir. SRTM verileri ABD için 1", diğer ülkeler için 3" çözünürlüklü olmak üzere NASA sunucuları üzerinden internette ücretsiz olarak yayınlanmaktadır.

Söz konusu veriler radar gölgelemesi, sinyal saçılması ve yansıması gibi nedenler yüzünden bazı bölgelerde (özellikle kıyı şeridi, sulak alanlarda ve sarp arazilerde) yer yer boşluklar içermektedir. Bu çalışmada kullanılan sayısal yükseklik modeli verileri yersel verilerle desteklenmiş, 3" çözünürlüklü SRTM yükseklik bilgisine dayanmaktadır. Söz konusu model Türkiye Sayısal Yükseklik Modeli (TSYM3) olarak adlandırılmaktadır (TSYM3 2008). TSYM3 modelinin Türkiye sınırları içinde doğruluğu 6 - 8 m olduğu ifade edilmekte, bitki örtüsü ile kaplı yerlerde ve topoğrafyanın düzensiz olduğu bölgelerde yükseklik doğruluğunun düştüğü gözlenmektedir (Bildirici vd. 2010). Nokta bazlı karşılaştırmalar yapıldığında dağlık ve ormanlık alanlarda bu doğruluk 20-25 m, düz ve çıplak arazilerde 3-5 m seviyelerindedir. Kiamehr ve Sgoberg (2005), çalışma bölgesiyle benzerlik gösteren İran sınırları içinde SRTM verilerinin doğruluğunu test etmiş ve bu verilerin jeoit modelleme işlemlerinde ve dolayısıyla gravite verilerinin enterpolasyonunda kullanılmasını önermiştir.

Sonuç olarak TSYM3'den elde edilen yükseklik bilgilerinin bu çalışma için Bouguer plakası etkisi ve arazi düzeltmelerinin hesabında yükseklik ihtiyacını karşılayacak nitelikte olduğu değerlendirilmiştir.

\subsection{Boşlukta ve Bouguer anomalilerinin hesabı}

Uygulama sahasındaki 2681 noktada boşlukta gravite anomalileri (5) eşitliği kullanılarak hesaplanmıştır. Şekil 4 hesaplanmış anomali değerlerine göre üretilmiş haritayı göstermektedir. Haritadan da anlaşılacağı üzere çalışma bölgesinde anomali değerleri $-25 \mathrm{mGal}$ ile $250 \mathrm{mGal}$ arasında değişmektedir. Şekil 3'deki topoğrafik durum ile birlikte değerlendirildiğinde bu anomali türünün topoğrafyaya bağımlılığı açık bir şekilde göze çarpmaktadır. Böylesi bir bağımlılık bu veriler üzerinden gridlenmiş veri türetmenin ne ölçüde sorunlu olduğunu kanıtlamaktadır.

Basit ve tamamlanmış Bouguer anomalileri ise sırasıyla (10) ve (12) eşitlikleri yardımıyla elde edilmiştir. Tamamlanmış Bouguer anomalisi için arazi düzeltmesinin hesaplanmasında küresel yaklaşım göz önünde bulundurulmuştur. Bouguer plakasını düzlem yerine küresel öngörmek topoğrafik etkiler için daha doğru sonuçlara ulaşmayı olanaklı kılmaktadır (örneğin bak. Vanicek vd. 2001). Arazi düzeltmesinin minimum, maksimum ortalama ve standart sapma değerleri sırasıyla $0.340,34.743,1.947$ ve $\pm 2.742 \mathrm{mGal}$ olarak hesaplanmıştır. Bu esaslar çerçevesinde, gravite ölçü noktalarında hesaplanmış basit ve tamamlanmış Bouguer anomalilerinin haritası sırasıyla Şekil 5 ve 6'da verilmiştir.

Jeoit modelleme için gravite anomalilerinin grid merkezlerine taşınması tercih edilen bir yaklaşımdır. Bu çalışmada grid aralığ1 (çözünürlüğü) gravite nokta verilerinin yoğunluğu göz önünde bulundurularak $3^{\prime} \times 3^{\prime}(\sim 5.6 \times 4.4 \mathrm{~km})$ seçilmiştir. Basit ve tamamlanmış Bouguer indirgeme büyüklükleri için kullanılacak topoğrafik yükseklik bilgileri aynı grid aralığı baz alınarak sayısal yükseklik modelinden türetilmiştir. Şekil 2'den de görüldüğü gibi, Bouguer anomalilerine iki aşamalı indirgeme işlemiyle ulaşılmaktadır. Bunlardan birincisi boşlukta indirgeme (önceki işlemle hesaplanmıştı),

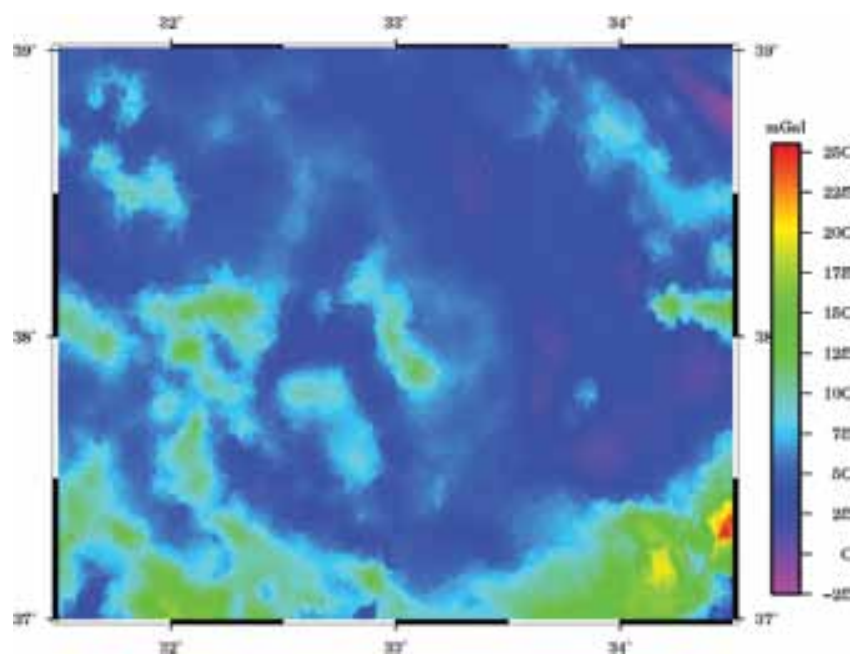

Şekil 4: Boşlukta gravite anomalileri 


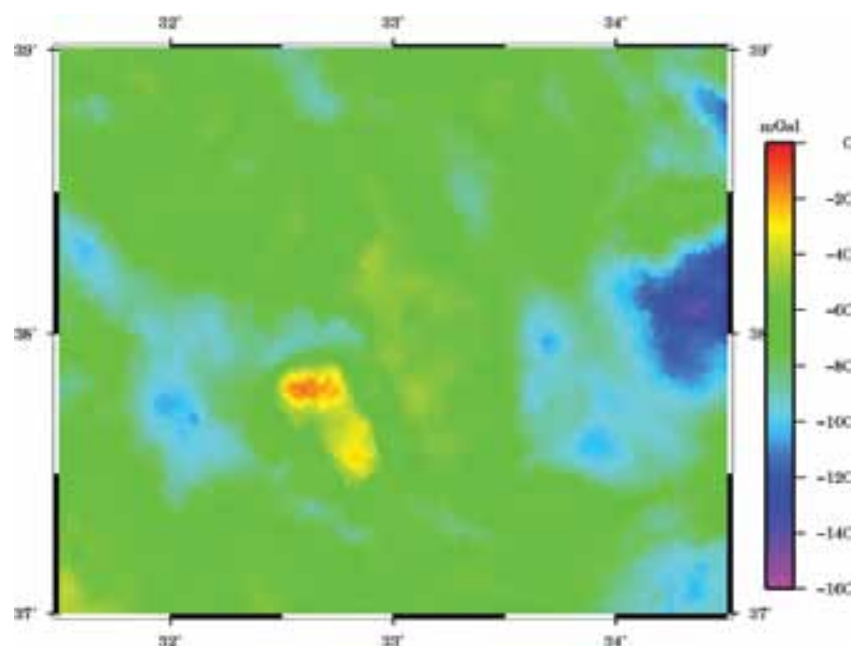

Şekil 5: Basit Bouguer anomalileri

ikincisi de Bouguer indirgemesidir. Bouguer anomalilerinin iki farklı yaklaşımla hesaplanmasında aşağıdaki işlem adımları uygulanmıştır.

Birinci yaklaşımda, rasgele dağılmış gravite noktalarında Basit Bouguer anomalileri doğrudan (10) eşitliği yardımıyla elde edilmiştir. $\mathrm{Bu}$ değerlerin grid merkezlerine atanmasında en yakın komşuluk ilişkisini temel alan enterpolasyon tekniği kullanılmıştır. Enterpolasyon işlemi Wessel ve Smith (1998) tarafından geliştirilmiş GMT yazılım araçlarından nearneighbour programıyla gerçekleştirilmiştir. Enterpolasyon parametreleri olarak enterpolasyona girecek noktalar için Bjerhammar (1973)'in deterministik kuralına göre en büyük yarıçap 12 derece dakikası, maksimum ve minimum dayanak nokta sayısı ise sırasıyla 6 ve 4 girilmiştir. Burada son işlem grid merkezlerindeki Bouguer anomalilerinin yeniden boşlukta gravite anomalilerine dönüştürülmesidir. Bunun için grid merkezlerinde TSYM3 verilerinin aritmetik ortalaması al1narak $3^{\prime} \times 3^{\prime}$ çözünürlüğünde yükseklik değerleri üretilmiştir. Bouguer plakası etkisi ortalama yüksekliklere göre hesaplanmıştır. Grid merkezlerindeki Bouguer anomali değerlerine, hesaplanan Bouguer plakası etkisi eklenerek boşlukta anomalilere dönüştürülmüştür.

İkinci yaklaşımda, rasgele dağılmış noktalardaki gravite değerleri (11) eşitliği yardımıyla tamamlanmış Bouguer anomalilerine indirgenmiştir. Arazi düzeltmesi küresel yaklaşımla $3^{\circ}$ lik integrasyon yarıçapına göre hesaplanmıştır. Grid merkezine indirgenmiş anomali değerleri basit Bouguer yaklaşımında olduğu gibi elde edilmiştir. Tamamlanmış Bouguer anomalilerinden boşlukta anomalilere dönüş işlemi (grid merkezlerinde) hem Bouguer plakası etkisini hem de arazi düzeltmesini içermektedir. Burada, arazi düzeltmeleri önce 1' çözünürlüklü olarak elde edilmiş sonra çözünürlük blok aritmetik ortalamaları alınarak 3' ya düşürülmüştür.

\subsection{Karşılaştırma}

Basit ve tamamlanmış Bouguer yaklaşımlarıyla elde edilen boşlukta anomalilerinin sonuçlar üzerindeki etkisini görmek için bir karşılaştırma yapılmıştır. Karşılaştırmaya geçmeden önce, çapraz geçerlilik (cross-validation) analizi gerçekleştirilmiştir. Çapraz geçerlilik testinin amacı gravite anomalilerinin (enterpolasyon sonrası) doğruluğu hakkında

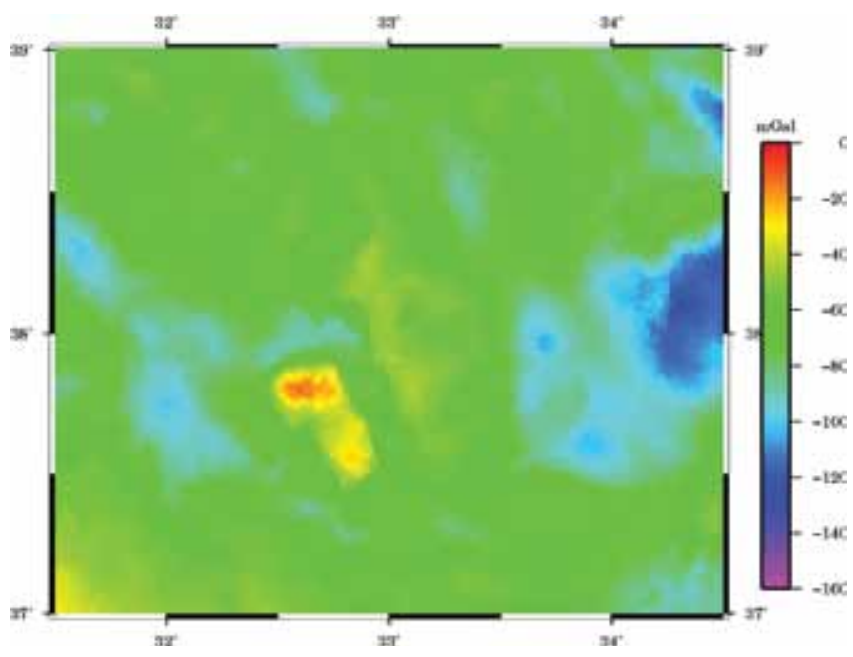

Şekil 6: Tamamlanmış Bouguer anomalileri

bilgi edinmektir.

Çapraz geçerlilik testinde uygulanan işlem adımları kısaca şu şekilde açıklanabilir. Veri kümesinde bir nokta seçilir, bu noktanın değeri o nokta hariç diğer tüm noktalara ait veriler kullanılarak uygun bir enterpolasyon tekniğiyle tahmin edilir ve gerçek değerle olan farkı bulunur. Bu işlem nokta kümesindeki tüm verilere sırayla uygulanır. Bütün farkların karesi alınıp toplanır ve bir karesel ortalama değer bulunur. Daha sonra diğer veri kümesi için de benzer şekilde bir karesel ortalama değeri hesaplanır. Veri gruplarından ortalama hatası küçük olanın göreceli olarak daha doğru olduğu kabul edilir (Kiamehr 2007).

Kiamehr (2007) ve bozucu gravite alanı büyüklükleri ile ilgili önceki çalışmalardan ortaya çıkan sonuçlar, gravite anomalilerinin enterpolasyonunda Kriging tekniğinin uygun olduğu işaret etmektedir. Bu nedenle, çapraz geçerlilik testinde test noktalarının enterpolasyonu Kriging tekniğine göre hesaplanmıştır. Kollokasyon tekniğinde olduğu gibi noktalar arasındaki uzaklıkların kestirim değerlerine verilerin ağırlık değerleri olarak katkı yapması, tercih edilen yöntemin avantajı olarak görülmektedir.

Çapraz geçerlilik sonuçları Tablo 2'de verilmiştir. Tamamlanmış Bouguer indirgemesinin, basit Bouguer yaklaşımına göre biraz daha küçük karesel ortalama hata ile sonuçlandığı görülmektedir. Her iki yaklaşımın medyan ve ortalama değerlerinin hemen hemen aynı olduğu dolayısıyla modeller arasında belirgin bir kayıklığın (bias) bulunmadığı söylenebilir. En küçük ve en büyük değerler arasındaki fark aralığı (farkların saçılımı), tamamlanmış Bouguer anomalilerinde biraz daha dardır ve bu sonuç karesel ortalama hataya 0.5 mGal'lik bir iyileşme olarak yansımıştır.

\section{Tartışma ve Sonuç}

Yeryüzünde ölçülen gravite değerlerinin jeodezide kullanımı, gravitenin değişik anomali türlerine indirgenmesini ve bu işlem sırasında ölçünün yapıldığı bölgenin topoğrafik

Tablo 2: Basit ve tamamlanmış Bouguer anomalileri için çapraz geçerlilik testi [mGal]

\begin{tabular}{|cccccc|}
\hline \hline Anomali & Min & Maks & Medyan & Ort. & KOH \\
\hline FA $^{\mathrm{SBA}}$ & -61.604 & 52.613 & 0.213 & -0.002 & 7.012 \\
\hline $\mathrm{FA}^{\mathrm{CBA}}$ & -47.847 & 57.769 & 0.201 & 0.002 & 6.554 \\
\hline \hline
\end{tabular}


durumunun dikkatli bir şekilde ele alınmasını gerektirmektedir. Bölgesel bir jeoit modelinin oluşturulması gibi çoğu uygulama bu verilerin gridlenmiş olmasını tercih ettiğinden, gravite indirgeme ödevinin bir ayağını da enterpolasyon oluşturur. Bu çalışmada jeoit modelleme için düzenli bir grid ağı biçiminde boşlukta gravite anomalilerinin $\Delta g_{F A}$ nasıl elde edileceği incelenmiştir. Boşlukta gravite anomalilerinin topoğrafyaya bağlı büyüklükler olması ölçü yapılmayan yerlerdeki enterpolasyonu zorlaştırmaktadır. Çözüm, bu anomali türünün topoğrafyadan çok daha az etkilendiği bilinen Bouguer anomalilerine $\left(\Delta g_{B}\right)$ dönüştürülmesidir. Böylesi bir dönüşüm sırasında topoğrafyanın sonuçlar üzerinde nasıl bir etki yarattığını görmek için Konya Kapalı Havzası olarak bilinen uygulama alanında 2681 gravite verisi kullanılarak bir uygulama gerçekleştirilmiştir. Uygulama grid noktalarında topoğrafik etki için basit ve tamamlanmış Bouguer yaklaş1mının karşılaştırılmasını kapsamaktadır.

Karşılaştırma, bu iki yaklaşımdan türetilmiş boşlukta gravite anomalileri üzerinden yapılmıştır. Anomaliler arasında, -6 ila $16 \mathrm{mGal}$ arasında değişen farklar vardır (Şekil 7). Söz konusu değerler jeoit modelleme işleminde önemli sayılabilecek farklardır. Fark artışlarının topoğrafyaya bağlı olarak engebeli ve yüksek bölgelerde olduğu gözlenmekte-

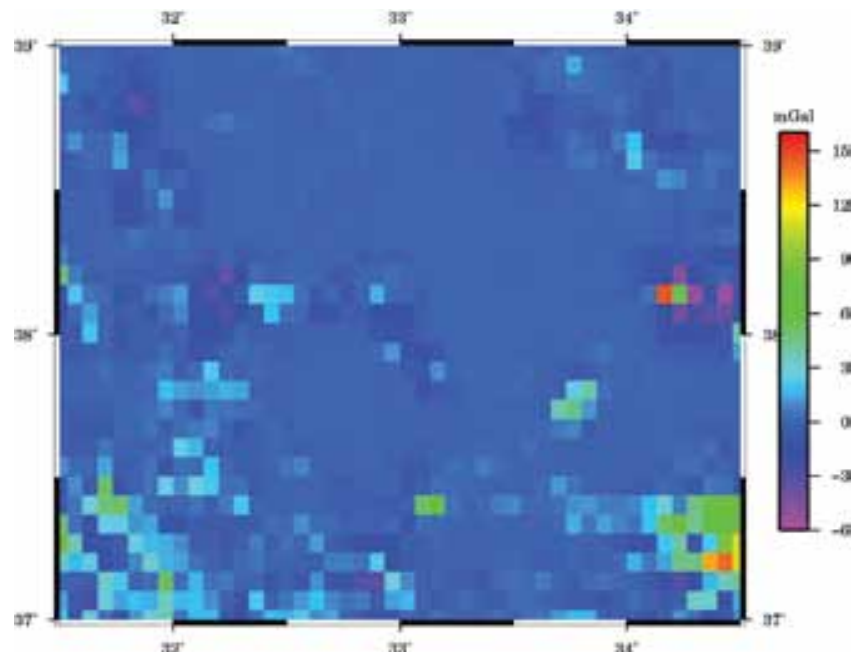

Şekil 7: Basit ve tamamlanmış Bouguer anomalilerinden türetilmiş boşlukta gravite anomalileri arasındaki fark haritası

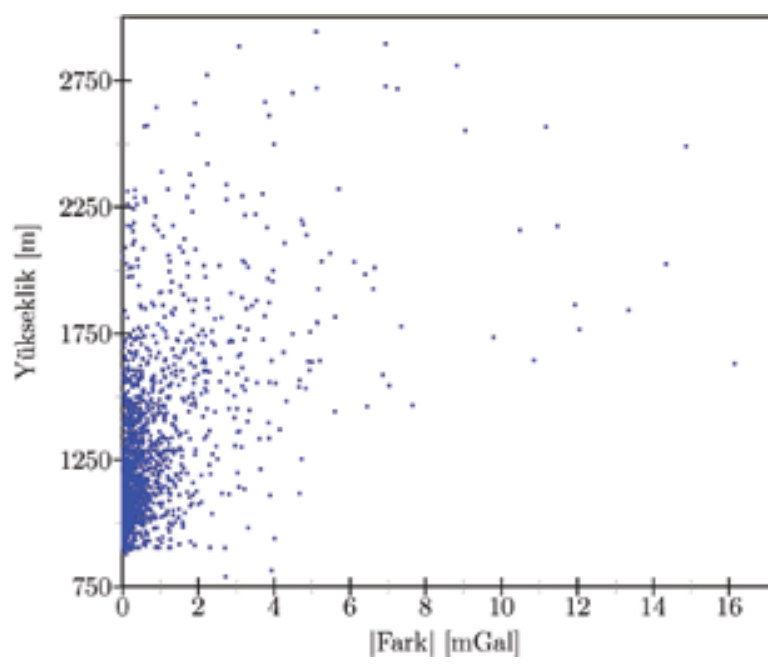

Şekil 8: Basit ve tamamlanmış Bouguer anomalilerinden türetilmiş boşlukta gravite anomalileri arasındaki farkların yükseklikle ilişkisi dir. Anomali farklarının topoğrafya ile ilişkisini belirlemek için, hem korelasyon analizi hem de mutlak fark - yükseklik grafiği çizilmiştir (Şekil 8). Analizi sonucunda korelasyon katsayısı 0.55 olarak hesaplanmıştır. Havzanın görece düz (yüksekliklerin 750-1200 m arasında değiştiği) kesimlerinde farkların çoğunlukla 2 mGal'den küçük, az sayıda noktada 2 - 4 mGal arasında kaldığı anlaşılmaktadır (Şekil 7 ve 8). Yüksekliklerin 1250 m'yi aştığı yerlerde farkların 4 mGal'i aştığ1, 1750 m'den sonra da 16 mGal'e kadar çıktığ 1 görülmüştür. Buradan, yüksek topoğrafik alanlarda ve topoğrafyanın çok düzensizleştiği yerlerde, basit $\left(\delta g_{S B}\right)$ ve tamamlanmış $\left(\delta g_{C B}\right)$ Bouguer indirgemesinin sonuçlar üzerinde anlamlı etkiye sahip olduğu sonucu çıkarılabilir.

Her ne kadar tamamlanmış Bouguer anomalisinin hesaplanma süreci zaman alıcı olsa da, yüksek doğruluklu jeoit hedefi için topoğrafyanın en ince ayrıntısı bile göz önünde bulundurulmalıdır. Konya Kapalı Havzası gibi kısmen dağlık, kısmen düzlük yerlerde basit ve tamamlanmış Bouguer yaklaşımı arasındaki farkın önemli olduğu anlaşıldığından özellikle dağlık alanlarda tamamlanmış Bouguer yaklaşımının enterpolasyon sürecinde mutlaka kullanılması gerekmektedir.

\section{Teşekkür}

$\mathrm{Bu}$ çalışmada kullanılan nokta gravite gözlemleri, Selçuk Üniversitesi Bilimsel Araştırma Koordinatörlüğü tarafından desteklenen 09-101-009 numaralı proje kapsamında Harita Genel Komutanlığı'ndan satın alınmıştır.

\section{Kaynaklar}

Anonim, (2000), World Geodetic System 1984: Its Definition and Relationships with Local Geodetic Systems, Teknik Rapor, National Imagery and Mapping Agency, Washington, USA.

Bildirici I. O., Ustun A., Ulugtekin N., Selvi H.Z., Abbak R.A., Bugdayci I., Dogru A. O., (2010), Compilation of digital elevation model for Turkey in 3-arc-second resolution by using SRTM data supported with local elevation data, Cartography in Central and Eastern Europe'un içinde, (Gartner G., Ortag F., Ed.), Lecture Notes in Geoinformation and Cartography, Springer, ss.63-76.

Bjerhammar A., (1973), Theory of Errors and Generalized Matrix Inverses, Elsevier, Amsterdam.

Featherstone, W.E., Kirby, J.F., (2000), The reduction of aliasing in gravity anomalies and geoid heights using digital terrain data, Geophysical Journal International, 141, 204-212.

Goos J.M., Featherstone W.E., Kirby J.F., Holmes S.A., (2003), Experiments with two different approaches to gridding terrestrial gravity anomalies and their effect on regional geoid computation, Survey Review, 37,92-112.

Heiskanen W., Moritz H., (1984), Fiziksel Jeodezi. Onur Gürkan (Çev.), KTÜ Basımevi, Trabzon.

Janak J., Vanicek P., (2005), Mean free-air gravity anomalies in the mountains, Stud. Geophys. Geod., 49, 31-42.

Kiamehr R., (2007), Qualification and refinement of the gravity database based on cross validation approach: A case study of Iran. Acta Geodaetica et Geophysica Hungarica, 42(3), 285295.

Kiamehr R., Sjoberg, E.L., (2005), Effect of the SRTM global DEM on the determination of a high-resolution geoid model: a case study in Iran. Journal of Geodesy, 79, 540-551. 
Kılıçoğlu A., Lenk O., Direnç A., Simav M., Yıldız H., Aktuğ B., Türkezer A., Göçmen C., Paslı E., Akçaya M., (2010), Türkiye izostatik gravite anomalisi haritası, Harita Dergisi, 144, 1-19.

Martinec Z., (1998), Boundary-Value Problems for Gravimetric Determination of a Precise Geoid, Springer-Verlag, Berlin.

Moritz H., (1992), Geodetic reference system 1980, Bulletin Geodesique, 66(2), 187.

Somigliana C., (1929), Geofisica-Sul campo gravitazionale esterno del geoide ellissoidico, Atti della Reale Academia Nazionale dei Lincei Rendiconti, 6, 237-243.

Stokes G.G., (1849), On the variation of gravity at the surface of the Earth, Trans. Cambridge Philos. Society, 8, 672-695.

Torge W., (1989), Gravimetry, Walter de Gruyter, Berlin.

TSYM3, (2008), 3" çözünürlüklü Türkiye sayısal yükseklik modeli, http://www.tsym3.selcuk.edu.tr.
Üstün A., (2001), GPS Nivelmanı yardımıyla ortometrik yüksekliklerin elde edilmesine yönelik jeoit belirleme yöntemleri, YTÜD Dergisi, 1, 62-82.

Üstün A., (2008), Fiziksel Jeodezi, Selçuk Üniversitesi Harita Müh. Bölümü Ders Notları (yayımlanmamış), http://193.255.245.202/ aydin/docs/fiziksel-jeodezi.pdf.

Vanicek P., Novak P., Martinec Z. (2001), Geoid, topography, and the Bouguer plate or shell. Journal of Geodesy, 75, 210-215.

Vanicek P., Tenzer R., Sjoberg L.E., Martinec Z., Featherstone W., (2004), New views of the spherical Bouguer gravity anomaly. Geophysical Journal International, 159, 460-472.

Wessel P., Smith W.H.F. (1998), New improved version of the generic mapping tools released. EOS Trans., 79(47), 579. 